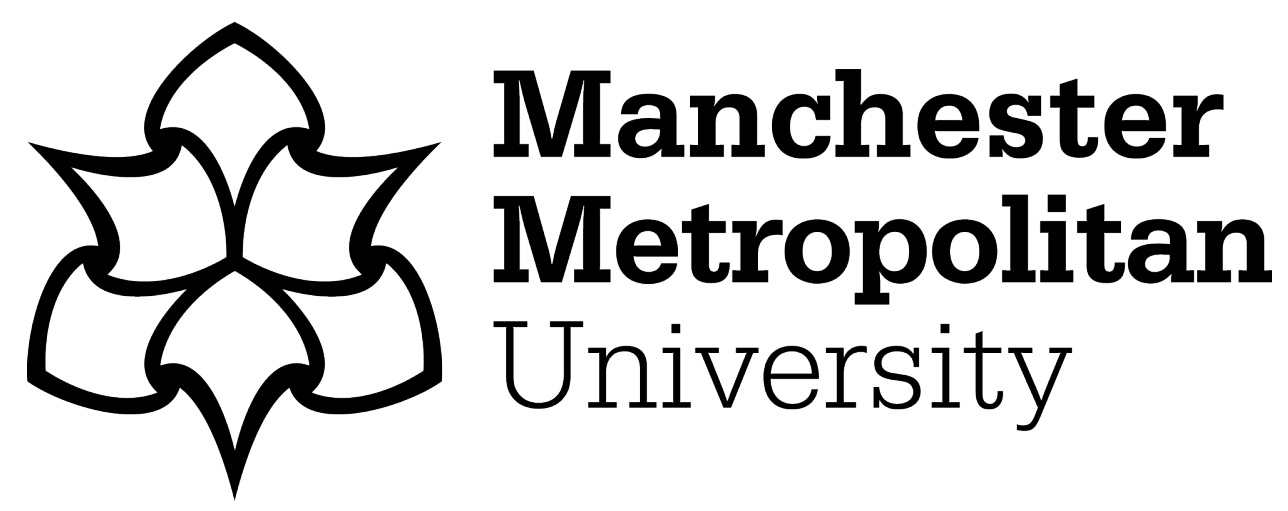

Wood, Max, Griffiths, John and Paltoglou, Aspasia Eleni (2021) Exploring difficulties in men's experience of self and agency during antidepressant use. Psychology of Men and Masculinity, 22 (2). pp. 298-305. ISSN 1524-9220

Downloaded from: https://e-space.mmu.ac.uk/626563/

Version: Accepted Version

Publisher: American Psychological Association

DOI: https://doi.org/10.1037/men0000330

Please cite the published version 


\title{
Exploring difficulties in men's experience of self and agency during antidepressant use
}

\author{
Maximillian Wood ${ }^{1}$ a, Dr. John Griffiths ${ }^{b}$, Dr. Aspasia E. Paltoglou ${ }^{b}$ \\ a University College London, and Camden and Islington NHS Foundation Trust \\ ${ }^{\mathrm{b}}$ Manchester Metropolitan University, Department of Psychology
}

\section{ABSTRACT}

Recovery from depression involves active processes of taking back control and reclaiming the self. Antidepressant medication can play a critical role in recovery, yet these medications and their effects can also become associated with feelings of dependency and loss of self, whilst conflicting with social norms, including gender roles. Men may be vulnerable in particular ways to these conflicts because of a dominant masculinity that demands independence and selfcontrol. High levels of non-adherence to prescribed antidepressant regimens in patient populations points to the importance of better navigating these socio-cultural and cognitive barriers in order to improve treatment outcomes. This study draws from one-on-one interviews with six men who speak about their experience of depression and antidepressants, and conducts a secondary thematic analysis of the data to explore the difficulties experienced around medication use, in particular in relation to these men's redefinition of self, and exercise of agency. The analysis exposed three themes: feelings of altered embodiment and reality, concerns about dependency, and the ambivalent nature of masculine roles. It suggests that increased agency for men with regards to their therapeutic regimen, and consideration of masculine ideals of control and responsibility, could improve the experience of antidepressant use. However, the discussion also recommends the integration of medication use within treatment models that challenge less healthy aspects of male roles and identities, and allow for a diversity of masculinities.

Key words: depression; antidepressants; masculinity; agency; self

\footnotetext{
${ }^{1}$ Corresponding author; maximillian.wood1@nhs.net
} 
Acknowledgments: The interviews used in this analysis were conducted by researchers from the Health Experiences Research Group, University of Oxford. Thank you to Susan Kirkpatrick and Damien Ridge (now Professor Damien Ridge, Professor of Health Studies at the University of Westminster).

Declarations of interest: none

Public significance statement: Adherence to antidepressant regimens is frequently poor, and patients express reservations around their use. These include difficulties related to sense of self, and identities such as gender roles. Men's conflicts around antidepressant use can be understood in the light of masculine norms, and treatment models designed to work with and around these norms could improve treatment outcomes for depression in male clients.

\section{INTRODUCTION}

Evidence-based guidelines recommend antidepressant medication as a first-line treatment for moderate to severe depression in adults (Cleare et al., 2015). Clinical trials support its efficacy, demonstrating it to be at least superior to placebo, though not always clinically significant in its effects (Cleare et al., 2015). Qualitative studies of user experience suggest that antidepressants can provide relief, allowing patients to get their "foot in the door" as they engage in a variety of purposeful activities on their journey to recovery (Knudsen et al., 2002; Lafrance, 2007). It has also been suggested that the biomedical model of depression may have a destigmatising effect for some people, by framing depression as a "biochemical" issue, on par with other physical illness (Schreiber and Hartrick, 2002).

However, despite these recommendations and positive findings, studies also report high rates of non-adherence to prescribed antidepressant regimens among patients, leading to suboptimal treatment, risk of relapse and poor quality of life (van Servellen et al., 2011). Studies report discontinuation rates over a six month period following prescription, ranging from 30\%-60\% depending on the population and type of antidepressant (Sirey et al., 2001; 
Demyttenaere et al., 2001; Sawada et al., 2009), such that from one in three up to over half of patients prescribed antidepressants may not adhere to the regimen, often without consulting their physician (Demyttenaere et al., 2001; Sawada et al., 2009).

Many users report concerns in relation to side-effects of the medication (van Servellen et al., 2011), including sexual dysfunction, nausea, headache, insomnia, cardiac arrhythmia, apathy and weight gain, as well as unpleasant symptoms related to discontinuation (Moret et al., 2009). Other variables thought to impact non-adherence include reports of "feeling better" before the end of the prescription period (Demyttenaere et al., 2001), preference for different treatment models, lack of social support, stigma, and patient scepticism about efficacy (van Servellen et al., 2011; Kamaradova et al., 2016).

Qualitative studies also suggest that users have concerns about a loss of agency and identity with regards to the medication (Cartwright et al., 2018). According to Bandura's social cognitive theory (Bandura 1982, 2006), to have agency is to be able to intentionally influence one's own life course, and 'self-efficacy' is a person's belief in their ability to execute courses of action required to deal with prospective situations. Research suggests that, for some users, antidepressant medication comes to be seen as a sign of "weakness", with difficulties arising especially in long-term use where users come to see themselves as dependent on the medication, thus undercutting their agency and self-efficacy beliefs (Cartwright et al., 2018; Fullagar, 2009). These conflicts are exacerbated by a wider cultural discourse in which emotional problems are seen as a sign of failure, and "man-made" mood-modifying medicines are considered to be "unnatural" (Stevenson and Knudsen, 2008). Antidepressant medication thus becomes a stigmatized medicine for an already stigmatized condition, and can be experienced as a threat to users' agency and identity at a time when this is most critical. 
One study found that social support may improve adherence to medication regimen, although only in those patients who have a high internal locus of control (Voils et al., 2005). There is also evidence that a strong sense of agency is related to lower risk of depression (Bandura, 2006) and to lower suicidal ideation, particularly in men (Bryan et al., 2014; Hobbs and McLaren, 2009). Furthermore, numerous qualitative studies investigating the lived experience of depression and recovery highlight recovery from depression as a process of "redefining the self" (Karp, 1994; Schreiber, 1996), implicating issues of belonging (BygstadLandro and Giske, 2017), and a "taking of responsibility" (Ridge and Ziebland, 2006) or "taking control" of one's depression (Fullagar and O'Brien, 2012).

Research on users' experience of antidepressant use has also highlighted the importance of sex and gender as important variables in expressions of conflict or concern about medication use (Gibson et al., 2018; Cartwright, 2018). These include dominant forms of masculinity or femininity - the norms, roles and practices held to be normative for males and females within a given culture, which are enforced, rewarded and re-created within the family unit and within wider social systems and institutions (Kimmel et al. 2005; Messerschmidt, 2018; Gibson et al., 2018). Despite the perception that men are usually averse to talking therapies and want a 'quick fix', studies suggest that men who do engage with mental health services prefer psychotherapy to medication as a treatment option (Hernandez et al., 2014), and that men are less likely than women to want to use prescription medication as a way of coping with stress (Liddon et al., 2017). These preferences can be expected to interact with and reflect masculinity practices and attitudes. It is noteworthy however that most existing research has investigated experiences of antidepressant use within female samples, whilst studies using male samples are considerably fewer, perhaps because depression is a condition stereotypically associated with women (Emslie et al., 2006; Schreiber, 1996). This is 
in line with research that suggests that men exhibit more externalized symptoms of distress, such as aggression, irritability, risk-taking and substance abuse, while women tend to exhibit more internalized symptoms, such as rumination and low mood, consistent with anxiety and depression disorders (Smith et al., 2018). But there is also evidence that clinicians and the medical establishment may underdiagnose depression in men because of clinician and measurement bias, and a lack of research in to the diversity of male experiences of depression (Smith et al., 2018).

An understanding of the male depression phenotype and men's attitudes to treatment is particularly important given that dominant forms of masculinity (as defined by researchers in North America, Western Europe and Australasia), are known to involve expressions of strength, independence, stoicism, responsibility, achievement and control (Emslie et al., 2006; Messerschmidt, 2018; Vogel et al., 2011). These dominant masculinities may make men susceptible in unique ways to the conflicts and stigma associated with depression and medication, and specifically so with regards to the themes of agency and self that are known to be critical in recovery from depression. Existing research on men's experiences of helpseeking and depression in the UK show how men seek to reconstruct a valued sense of themselves and their own masculinity during recovery (Emslie et al., 2006). More specifically, men report struggling to reclaim the strength and independence that is threatened by the lived experience of depression, but is demanded of them by dominant gender norms and practices (O'Brien et al., 2005; Emslie et al., 2006). Research also suggests that depression can be perceived as a risk to one's 'status' relative to other men and women (Courtenay, 2000) and that men show strength through restricted emotionality and denial of vulnerability (Gough 2013; Steward and Harmon, 2004). 
A study by Gibson et al. (2018), using a sample of men from New Zealand, undertook an investigation on men's conflicts specifically about antidepressant use, and demonstrated how participants navigated conflicts between the use of medication and masculine norms and practices, in particular in relation to issues of control, sexual performance, emotion, and autonomy. To the best of our knowledge, however, no other studies have yet taken as their primary objective an investigation of how men's experiences of antidepressant use interact with dominant masculinities, and no studies have investigated this in particular with relation to the construction of agency in recovery. Improving efficacy of existing treatments models for depression in male populations may hinge on a better understanding of precisely these variables.

This paper seeks to motivate discussion on this topic by presenting an analysis of interviews with a sample of six men who agreed to speak about their experience of depression and antidepressant use. The analysis was conducted with a view to exploring the following questions: What difficulties can negative perceptions and experiences of antidepressant medication pose to men's redefinition of self, and exercise of agency, in their recovery from depression? And in what ways do antidepressants sometimes conflict with the participants' masculinity in this process of recovery?

\section{METHODOLOGY}

\section{Participants}

Participants were selected by reviewing people's profiles on the 'depression' and 'experiences of antidepressants' pages in the mental health section of the healthtalk.org website, run by 
the DIPEx charity in partnership with the Health Experiences Research Group (HERG) at the Nuffield Department of Primary Care Health Sciences, University of Oxford. The website publishes people's individual accounts of living with various physical and mental health conditions, collected by academic researchers who interview participants in their own homes. The archive includes over four thousand narrative interviews approved for secondary analysis. The stories are collected for research purposes and are publicly shared online with the aim of helping others to feel better prepared and informed, and less alone in their lived experience. Inclusion criteria for the study presented in this paper were that the participants be adult males, having received a diagnosis of a depressive disorder, and with evidence on the website profile of having taken antidepressant medication. There were no exclusion criteria. All 74 profiles on the 'depression' and 'experiences of antidepressants' pages were screened, and 22 met criteria. Six were selected to give a range of ages, and a balance of positive and negative experiences with medication use, as evidenced from the interview excerpts on the website. A maximum of six transcripts were available for analysis because of restrictions in the data sharing agreement signed by Manchester Metropolitan University and Oxford University for the purposes of this study.

The final sample included six men, aged between 29 and 75 at the time of interview, drawn from various locations throughout the United Kingdom. Participants varied in how recently they had been diagnosed, what kinds of antidepressant they had taken (including Sertraline, Venlafaxine/Effexor, Paroxetine and Fluoxetine/Prozac), and whether they were still taking antidepressants at the time of the interview. Two participants also reported taking lithium. Four participants were married or in a relationship (two of whom had children), and two were single. One participant was identified as belonging to a minority ethnic group. The interviews were conducted by a female or male sociologist from the HERG, whilst the 
secondary analysis presented in this study was conducted independently at a later date by a male researcher, who has never received a diagnosis of depression. The names referenced below are pseudonyms given to the participants for the purposes of this paper.

\section{Data collection}

The interviews were conducted over the course of separate studies by the HERG between 2003 and 2012. Participants were recruited through social media, patient support groups, newsletters, word of mouth, GPs and other clinicians, and took place one-on-one in the participants' homes. For the four interviews drawn from the 'experience of antidepressants' section of the HERG archive, the interviewer first asked participants to recount their story, in particular when their depression first started, how they sought help, what medications they were given, and what effect these have had. The interviewer then asked follow-up questions, including targeted questions about side-effects of the medication. For the two interviews taken from the 'depression' section, the interviews were more open-ended. Respondents were given as much time as required to talk about their lives in their own words, and to focus on issues about depression that were important to them. A topic list was then used in the second part of the interview, including life before depression, the period of time when things seemed 'not quite right', the depression experience, social consequences of depression, help seeking and personal coping strategies. All interviews were audio recorded, some were also video recorded. The interviews were not time-limited, lasting up to a couple of hours in some cases. The interviews were professionally transcribed and returned to participants for review. Qualitative thematic analyses of the transcripts, illustrated with excerpts from the interviews, 
have been published by the HERG on the healthtalk.org website, as well as in publications in health and social science peer reviewed journals (ex. Emslie et al. 2006).

\section{Data analysis}

A critical realist orientation was adopted in asking the research questions that are concerned primarily with the content and process of the participants' experience, whilst looking to the material and social realities that shape the production of this experience (Ussher, 2010). Critical realism is a methodological framework that aims to understand the causal mechanisms underlying social phenomena. Critical realism relies on theories and researcher-driven analysis to explore theory-guided questions, in contrast with more datadriven frameworks such as Grounded Theory (Fletcher, 2017). As Fletcher (2017) illustrates, the critical realism researcher's investigation alternates between the three levels of reality; namely the individual's experience of an event or phenomenon, the event itself, and the causal mechanisms underlying the event.

A thematic analysis was conducted on the transcripts, according with the methodological and epistemological approach of much existing research on the topic that has asked similar research questions of similar data (e.g. Gibson et al., 2018; Cartwright et al., 2018). Following a pre-coding familiarization stage (Braun and Clarke, 2006), the transcripts were coded using manual scrutiny-based coding techniques (Ryan and Bernard, 2003). Preexisting codes were not imposed on the data, though the coding was informed by the existing literature, and the specificities of the research question, such that all themes related to agency, self, masculinity, recovery and antidepressants were extracted, whilst some themes were also extracted more inductively, prompted by the transcripts themselves. Following initial coding, 
codes were grouped in to sub-themes and finally themes, with an attempt to capture only those themes directly relevant to the research question, without losing the complexity and novelty presented by the data itself. Three themes were included in the final analysis. The lead researcher was responsible for coding the six transcripts. Unfortunately, double coding with another researcher was not undertaken in the initial analysis, and the codes had to be disposed of before a second data sharing agreement could be signed to allow other researchers to code the data. Another two researchers did code one of the transcripts at a later date and found evidence for the final themes identified by the lead researcher. Ethical approval for the analysis was granted by the Psychology Department Research Ethics Committee at Manchester Metropolitan University.

\section{RESULTS}

\section{Unreality and disembodiment}

Perceived distortions in sense of self and exercise of agency, associated with a sense of altered reality and dissociated embodiment, attributed by users as a side effect of the antidepressant medication, are well reported in existing research (Read et al., 2014; Gibson et al., 2018), and our participants also voiced these concerns. For Tom, one of the most pronounced negative effects attributed to the medication was a sense of unreality and disembodiment:

"One of things that I do remember was feeling a sense of distance from the world a bit, I felt [um] kind of like what was happening wasn't really happening" [...] "almost like I'm, I'm watching what's going on, I'm not quite fully in my body I'm not fully 
there [um] and, you know, both pleasure and pain aren't really experienced to the full extent" (Tom)

This concern is consistent with the findings from the Gibson et al. (2018) study, in which the men reported being particularly concerned with loss of vitality and sensory engagement, rather than loss of empathy or concern for others, which research has suggested may be more often reported as a concern for women (Fullagar and O’Brien, 2012). Harry reports a numb "dream like state" when he first started taking the medications, whilst George reports "feeling constantly flat", which impacts on his ability to write music, an identity defining occupation linked with enjoyment:

"Oh yeah well the first time I started.... completely woozy, completely numified, in a dream like state." (Harry)

"The only problem that I did find with, with lithium, and again with, with, with Effexor is it took, it took me away from me, if you wish. [um] I was no longer myself. [um] I was no longer able to do some of the things which I liked doing. I liked writing music and I was, I was unable to do that" (George)

"You know, the idea of, [um] recovering from depression is to make yourself feel well again and start enjoying life, but if you're taking pills which stop you enjoying life, well, [laugh] you know, [...] feeling constantly flat." (George) 
Another loss of sensuality and enjoyment reported by some participants related to sexual irregularities, with repercussions for the men's roles as partners within intimate relationships. Tom for example noticed a loss of libido, which he connected with the sense of unreality and disembodiment, an issue also reported by Peter, which impacted on his relationship with his wife:

"I think probably loss of libido to an extent was a [um] which kind of links to what I was saying before about just that kind of sense of distance from the world" (Tom)

"I can always remember my wife and, the psychiatrist had to see my wife and she complained, she said it was the [um] it was the pills that were making me not interested in sex" (Peter)

Giddens (1991) suggests that routine control of the body is integral to the experience of agency, as well as carrying on normal functions consistent with an individual's biographical narrative - yet as observed this can come to be disrupted by the loss of sensuality and altered embodiment that participants observed consequent to taking the medication. Other abnormalities reported by participants included difficulty with ejaculation:

"with Seroxat the first thing I noticed was, [laughs] this is a bit embarrassing, but I couldn't ejaculate..." (Samuel)

"Yes. [um] I believe the technical terms is delayed ejaculation" (George) 
Women also struggle with the sexual side effects of antidepressant medication (Mullen et al., 2014), though dominant forms of masculinity are tightly bound to norms of sexual "performance" and penetrative intercourse in particular, with loss of libido or erectile problems signifying a failure of masculinity (Fergus et al., 2002). In this vein, and as noted in the study by Emslie et al. (2006), which draws from some of the same interviews, compared to the loss of libido, participants tried to re-frame difficulties with delayed ejaculation in a masculinity affirming light by making the analogy with being a "porn star":

"you know, l'd be a hell of a porn star because l'd keep going for hours [laugh]" (George)

"you feel like a sort of porn star, you can go for hours you know [laughs]" (Samuel)

Yet despite trying to reframe the situation, participants were unable to fully normalize this new form of embodiment, and it removed enjoyment of sexual activity, which previous research has suggested may become a source of distress in itself and further increase feelings of depression (Gibson et al., 2018).

"you just think whoa, there's something fucked up in my body [laughs], this isn't the way it was supposed to be." (Samuel)

"Yeah and I, it was kind of annoying, [um] you know, because after half an hour of our banging away, nothing's happening. You know [laugh] you kinda get a bit, bit tired." (George) 


\section{Uncertainty and dependency}

Alongside the difficulties associated with an altered sense of reality and embodiment, attributed as side effects of the medication, the men also reported conflicts at more "symbolic" and "narrative" levels (Knudsen et al., 2002) related in part to their own insight in to the roots of their depression. Indeed, whilst participants adopted both biochemical and psychosocial perspectives in their accounts, some were clear in preferring the latter model:

"I: So would you say that talking about it was more powerful than taking medicines?

R: Yeah, yeah, yeah, yeah. I felt when I did the therapy, the group therapy and one to one, I thought that most, most valuable" (Peter)

"the brain is something that develops in life it isn't like a machine that's fixed at birth and it is also continually changing and certainly in our early years [um] and it, you know, it changes in response to the relationships and experiences that we have." (Tom)

Medication use was perceived as undermining the self-understandings and "recovery narratives" (Danielsson et al., 2009) that some participants had gained through therapy or other non-pharmaceutical efforts at recovery, confounding their agency and self-efficacy:

"I had no way of gauging what was making me feel better, you know, was it the pills, was it the psychotherapy that I was doing [um] was it my circumstances, what was it 
I didn't know and pills were at that moment part of that mix [...] I had a sense that it was the discussions I was having through the therapy but I didn't really know" (Tom)

“my experience with [um] with the drugs is that I don't know that they're not working [...] I don't know that, I can't say they are working as I don't know whether it's my - additional efforts of just going to see the counsellor once a week" (Harry)

This state of uncertainty and self-doubt accords with the findings from the studies by Fullagar (2009), and Lafrance (2007), in which the participants' non-pharmaceutical therapeutic practices were made invisible by the authority invested in biomedical narratives. Faced with an uncertainty as to the real foundations of one's recovery, participants also reported a fear of discontinuing the medication, despite a belief that the medications do not really "make any difference"

"I felt, I just kept on the tablets, I felt they didn't, I just took them, I felt they didn't make any difference to me really but I've always been frightened of coming off them and in all my time having antidepressants" (Peter)

"Yeah you're terrified of what is going to happen now. If you said to me okay, stop taking Prozac tomorrow, I wouldn't be able to." (Samuel)

A state of passive dependence and submission to medical advice is adopted, which we might consider to be a form of what Frankenberg (1992) calls the "tragic inevitability" that can come 
to permeate the identity of the "sick" patient, hindering the building of an agentic self that is otherwise crucial to recovery:

"I just kept taking the pills and doing what people told me." (Peter)

Tom describes the feeling of disempowerment induced by his fear of discontinuing the antidepressants, representing a damaging loss of self-efficacy (Bandura, 2006). He describes a state of self-alienation in which he disengages from his feelings, and develops a sense of irresponsibility and externality from himself, mirroring at the level of emotion and identity the dissociative embodiment noted in the previous theme:

"I've come to a point where I've sort of stopped engaging with how I might feel and I'm just kind of now saying this pill will just kind of get me through the day and then I developed a fear whereby I would be like if I stop taking this pill I'm not going to, I'm going to be back where I was [um] which is quite a disempowering thing" (Tom)

"it was a kind of psychological almost like a sort of dependency, like the only reason I'm feeling okay is because of this pill, it's a kind of external xxx sort of feeling. [Um] and I felt that and I was actually kind of possibility quite negative because I wasn't taking responsibility for my own health in a way" (Tom)

Work by Williams (1984), and other researchers (Stevenson and Knudsen, 2008), suggests that recovery from illness involves processes of "narrative reconstruction" in which the course of 
the illness is explained in such a way as to reaffirm the impression that life has a course and the self has a purpose. In this light, the conflicts expressed by our participants suggest that perceptions of antidepressant use can come to disrupt processes of narrative reconstruction by becoming associated with a sense of self-alienation and uncertainty about the real determinants of the life course, and the devaluing of one's purposive efforts as sources of real change.

\section{Functional zombies}

Participants were able to reflect on the ambivalent nature of their masculine roles and identities as both a positive and negative factor in their depression. George for example makes the observation that his duties as a husband and father provided a structure and purpose that gave him direction and pushed him to "keep going" during the hardest times, but also placed a burden of responsibility on him that foreshortened his recovery:

"In a way sort of the, the weight of the responsibilities of being a husband and a father kind of helped because it meant that I had to keep going. That there wasn't an option. [um] It would have been very easy to sort of sign off sick from work. It would have been very easy to do that. And certainly in my own case, that would have been the wrong thing to have done because then I would have lost the structure in life." (George) 
"...but if you could have taken away the responsibilities and the pressure, possibly even keeping the routine or substituting it with a different routine, then, yeah I think I would have got better a lot quicker" (George)

Peter describes a similar nuance. He is proud of having had the "guts to carry on" and fight to provide a "normal life" for his family, but he is also aware that work and money pressures exacerbated his depression:

"it was a fight to keep going and living with it and trying to live a normal life, you know, because I've done well because I've brought up a family and got a house and a car and I've worked all the way through which is unusual for a depressive really. So I feel I've been lucky and I've a lot of guts to carry on with it and I've always carried on as I say, I used to crawl, to make sure I had a shave and I've always tried to be alright with the kids and I've forced myself to go to work as often as I could" (Peter)

"I get promoted to be a planning manager [um] and that was a step too far because I was unhappy in that, I was getting more and more depressed again" [...] "how money rules you" (Peter)

Gibson et al. (2018) highlight the importance that men attribute to their role as the family breadwinner, whilst Emslie et al. (2006) note how these responsibilities may precipitate depression by creating stress. However, these studies do not identify the ways in which medication may come to play a role in this cycle by being seen as a way to allow men to cope with more stress, without changing underlying routines or stresses. George for example points 
to how medication became a tool that allowed him to function, but didn't address the root cause of his depression, thus making him a "functional zombie":

"it kind of worked in that it made me more functional. I was a functional zombie. I, I, I could function, I could work, I could read, I did have my motivations, my mental capacities back but I was still depressed." (George)

Peter reflects on how he had wanted to quit his job, but did not do so out of a sense of duty to his family, so he continued to take the medication, as a way to just "carry on":

\footnotetext{
“it was something I wanted to do but I didn't feel like putting my wife and my family through difficulties to please myself" (Peter)
}

"I just did things, I just went from day to day, take my pill, carry on" (Peter)

Our analysis suggests that it is important to recognize how medication can come to be deployed simply to allow men to continue being "strong" and carry the heavy burden of responsibilities that may be a contributing factor to the causes of their depression in the first place. Gibson et al. (2018) report how men may use stoic language or masculinity affirming metaphors of combat in describing their "fight" against depression, yet our participants also pointed to important processes of "acceptance" and identity change as critical to their recovery, pointing towards alternative non-combative models for tackling depression: 
"Getting better is about thinking no that's wrong actually, and moving on, it's not about fighting" (Samuel)

"I think I've kind of accepted that that it is something that's there now." (Samuel)

"you can fabricate the personality to try and fit into kind of social conventions and social rules and you can actually have a very poor sense of your own identity and that's quite a painful process to actually think about and accept that [um] but I do personally speaking find that to be quite convincing." (Tom)

\section{DISCUSSION}

The above analysis highlights how certain experiences of altered reality and embodiment including sexual abnormality, disembodiment and dissociation, and loss of enjoyment and creative vitality - attributed as side effects of the medication by participants, can come to be experienced as disrupting identity-defining roles and activities. These included the men's roles as intimate partners, but also more generally their ability to enjoy and create, perceived by some participants as part of what was hoped for in recovery. This concurs with much previous research on the importance of physical side-effects on user experience of antidepressants (Read et al., 2014; Cartwright et al., 2018), and on how this may become gendered in particular ways (Gibson et al., 2018).

The above analysis also highlights the centrality of conflicts at psychological, symbolic and narrative levels as critical to users' attempts to rebuild their sense of identity, agency and self-efficacy in the process of recovery. The men reported not only losing touch with their 
bodies and sensuality, but also lost touch with the validity of their own introspections, and a sense of narrative coherency in which they could account for their behaviour and internal states. Recovery from illness involves processes of "narrative reconstruction" in which the course of the illness is explained in a life-affirming way (Williams, 1984), yet antidepressants can come to be associated with self-alienation and uncertainty about the real determinants of the life course, and the devaluing of one's agency as a source of change. These difficulties are further intertwined with concerns about dependency on the medication, and fear of withdrawal.

Our study also demonstrates how medical and psychotherapeutic practices and narratives can come in to conflict. As other studies have pointed out, availability of clear information about side effects and withdrawal, and the development of a good rapport between the prescribing doctor and patient, can facilitate the integration of the different models of intervention. This would allow medication users to validate insights in to the sources of their depression, and play a more agentic role in establishing their own therapeutic regimen (Garfield et al., 2003). Our study suggests that commitments at the heart of the male gender identity to do with independence and control may also need to be addressed if this integration is to occur successfully, concurring with findings from other studies (Emslie et al., 2006; Robertson et al., 2015), such that men can frame their medication use as an expression of control, instrumental change and responsibility.

Finally, our study raises questions about using medication as a technology that allows men to "cope" with typically masculine roles and responsibilities that may in fact be one of the stresses contributing to their depression, in particular those of husband, father and "breadwinner", although these paradoxically also provide an important sense of structure and purpose. As Seidler et al (2018) recommend, services may benefit from acknowledging the 
contributions of positive masculinities, supporting and promoting men's diverse patterns of masculinity, whilst also creating safe spaces where men can challenge the more destructive patterns of masculinity. Indeed, it has been suggested that conflicts around different components of the male identity may be differentially related to depression. Conflicts around success and achievement seem to be key variables that determine vulnerability to depression, as opposed to issues of restricted emotionality, which may be more closely associated with attitudes to help-seeking (Good and Wood, 1995; Robertson et al., 2015). Medication use could be integrated with other forms of support that foster self-acceptance and the development of more healthy forms of masculinity and work-life balance, allowing men to restructure their lives to decrease stress whilst still maintaining purpose and responsibility.

Health education and training oriented to methods for engaging men in treatment models could better equip clinicians with the knowledge and skills needed to support male clients (Seidler et al. 2018), without also becoming complicit in reinforcing dominant models of stoicism and emotional detachment where this is not expedient to recovery. Research exclusively and explicitly focusing on men is also essential in order to better understand the male depression phenotype and disentangle it from traditional biased views (Smith et al., 2018). Addressing men's complex lived experience of antidepressant use could help to make mental health services more accessible to this currently underrepresented population (Affleck et al., 2018; Seidler et al., 2018), and maximize the effectiveness of antidepressants as part of a wider set of practices aimed at alleviating depression and promoting agency.

The analysis presented in this paper aims to generate further research on a topic that has critical ramifications for men's mental health and effective clinical practice. Future research should aim to transcend the limitations faced in this study. Conducted without external funding, this study was limited to analyzing secondary data, with a small sample size. 
The appropriate analytic method for such a small sample is open to question, and interpretative phenomenological analysis may have been more appropriate. However, thematic analysis as a method is open to the flexible application of theories along a range of epistemological positions (Braun and Clarke, 2006), and was a good fit with the critical realist orientation of the research questions, allowing the interpretation of both experiences and their context (Bonnington \& Rose, 2014).

The selection of transcripts to be analyzed was also non-randomized, picked deliberately from a small subsection of the HERG archive by the lead researcher to give a selection of attitudes towards antidepressant medication, and produce a range of ages. Only one participant was of a minority ethnic group, none were aged below 29 , and none openly identified as bi- or homosexual on the healthtalk.org website. Given the small sample size, homogeneity may actually be advantageous (rather than having 'token' participants singularly representing different backgrounds), and more homogeneity in terms of age in our sample may have been preferable, given generational differences in masculinity. But future research with larger random samples should aim to engage a diverse range of participants. Moreover, whilst this paper benefitted from co-authorship and review, the main analysis was conducted primarily by the one lead researcher, who has his own reservations about the normalization of antidepressant use, and his own gendered identity.

This paper has foregrounded some key themes and questions to be explored further. These include not only issues of altered embodiment and dissociation in medication use, but also the role of life-narratives and the construction of an agentic self in recovery, as well as the interaction between medication use and the ambivalent nature of masculinities that seem to both constrain but also empower men in their recovery. An open engagement with these difficulties and concerns around antidepressant use in men, set in the context of a validating 
but also critical discussion on masculinity, may help to make psychopharmacological treatment for depression more effective and accessible for male populations, and better integrated with other treatment modalities, including psychotherapy and other self-led efforts at recovery.

\section{REFERENCES}

Affleck, W., Carmichael, V., Whitley, R., (2018) ‘Men's Mental Health: Social

Determinants and Implications for Services', The Canadian Journal of Psychiatry, 63(9), 581-589.

Bandura, A., (1982) 'Self-efficacy mechanism in human agency'. American Psychologist, 37(2), pp. 122-147.

Bandura, A., (2006) 'Towards a psychology of human agency', Perspectives on Psychological Science, 1, pp. 164-180.

Braun, V., and Clarke, V., (2006) 'Using thematic analysis in psychology', Qualitative Research in Psychology, 3(2), pp. 77-101.

Bryan, C. J., Andreski, S. R., McNaughton-Cassill, M., and Osman, M., (2014) 'Agency is associated with decreased emotional distress and suicidal ideation in military', Archives of Suicide Research, 18, pp. 241-250. 
Bonnington, O., and Rose, D., (2014) 'Exploring stigmatisation among people diagnosed with either bipolar disorder or borderline personality disorder: A critical realist analysis' Social Science \& Medicine, 123, 7-17.

Bygstad-Landro, M., and Giske, T., (2018) 'Risking existence: The experience and handling of depression', Journal of Clinical Nursing, 27(3-4), pp. e514-e522.

Cartwright, C., Gibson, K., and Read, J., (2018) 'Personal agency in women's recovery from depression: The impact of antidepressants and women's personal efforts', Clinical Psychologist, 22(1), pp. 72-82.

Cleare, A., Pariante, C. M., Young, A. H., Anderson, I. M., Christmas, D., Cowen, P. J., Dickens, C., Ferrier, I. N., Geddes, J., Gilbody, S., Haddad, P. M., Katona, C., Lewis, G., Malizia, A., McAllister-Williams, R. H., Ramchandani, P., Scott, J., Taylor, D., Uher, R., (2015) 'Evidence-based guidelines for treating depressive disorders with antidepressants: A revision of the 2008 British Association for Psychopharmacology guidelines', Journal of Psychopharmacology, 2015, 29(5), 459-525.

Courtenay, W. H. (2000). 'Constructions of masculinity and their influence on men's wellbeing: A theory of gender and health.', Social Science \& Medicine, 50(10), 1385-1401.

Danielsson, U., Bengs, C., Lehti, A., Hammarström, A., and Johansson, E. E., (2009) 'Struck by lightning or slowly suffocating - gendered trajectories into depression', BMC family practice, $10(1)$, pp. 56-56. 
Demyttenaere, K., Enzlin, P., Dewe, W., Boulanger, B., De Bie, J., De Troyer, W., and Mesters, P., (2001) 'Compliance with antidepressants in a primary care setting: beyond lack of efficacy and adverse events', Journal of Clinical Psychiatry, 62, 30-33.

Emslie, C., Ridge, D., Ziebland, S., and Hunt, K., (2006) 'Men's accounts of depression: Reconstructing or resisting hegemonic masculinity?', Social Science \& Medicine, 62(9), pp. 2246-2257.

Fergus, K. D., Grey, R. E., and Fitch, M. I. (2002) 'Sexual dysfunction and the preservation of manhood: Experiences of men with prostate cancer', Journal of Health Psychology, 7, pp. 301-316.

Fletcher, A. J., (2017) 'Applying critical realism in qualitative research: methodology meets method', International Journal of Social Research Methodology, 20(2), pp. 181194.

Frankenberg, R. (1992) 'Your time or mine: Temporal contradictions of biomedical practice', Time, Health and Medicine., ed. Frankenberg, R., London: Sage.

Fullagar, S., (2009) 'Negotiating the neurochemical self: anti-depressant consumption in women's recovery from depression', Health, 13(4), pp. 389-406. 
Fullagar, S., and O'Brien, W., (2012) 'Immobility, battles, and the journey of feeling alive: women's metaphors of self-transformation through depression and recovery', Qualitative health research, 22(8), pp. 1063.

Garfield, S., Smith, F., and Francis, S., (2003) 'The paradoxical role of antidepressant medication - returning to normal functioning while losing the sense of being normal', Journal of Mental Health, 12(5), pp. 521-535.

Gibson, K., Cartwright, C. and Read, J., (2018) 'Conflict in Men's Experiences With Antidepressants', American journal of men's health, 12(1), pp. 104-116.

Giddens, A., (1991) Modernity and self-identity. Cambridge: Polity Press.

Good, G. E., and Wood, P. K., 'Male gender role conflict, depression, and help seeking: do college men face double jeopardy?', (1995) Journal of Counselling and Development, 74, 70-75

Gough, B. (2013) 'The Psychology of Men's Health: Maximizing Masculine Capital', Health Psychology, 32(1).

Hernandez, C. A. S., Oliffe, J. L., Joyce, A. S., Söchting, I., and Ogrodniczuk, J. S., (2014) 'Treatment preferences among men attending outpatient psychiatric services', Journal of Mental Health, 2014; 23(2): 83-87. 
Hobbs, M., and McLaren, S., (2009) 'The interrelations of agency, depression, and suicidal ideation among older adults', Suicide \& life-threatening behavior, 39(2), pp. 161-171.

Kamaradova, D., Latalova, K., Prasko, J., Kubinek, R., Vrbova, K., Mainerova, B., Cinculova, A., Ociskova, M., Holubova, M., Smoldasova, J., Tichackova, A., (2016) 'Connection between self-stigma, adherence to treatment, and discontinuation of medication', Patient Preference and Adherence,10, 1289-1298.

Karp, D. A., (1994) 'Living with depression: Illness and identity turning points', Qualitative Health Research, 4(1), pp. 6-30.

Kimmel, M. S., Hearn, J., Connell, R. W., (2005) Handbook of studies on men and masculinities, Sage Publications.

Knudsen, P., Hansen, E. H., Traulsen, J. M. and Eskildsen, K., (2002) 'Changes in SelfConcept While Using SSRI Antidepressants', Qualitative Health Research, 12(7), pp. 932944.

Lafrance, M. N., (2007) 'A Bitter Pill: A Discursive Analysis of Women's Medicalized Accounts of Depression', Journal of Health Psychology, 12(1), pp. 127-140.

Liddon, L., Kingerlee, R., and Barry, J. A., (2017) 'Gender differences in preferences for psychological treatment, coping strategies, and triggers to help-seeking', British Journal of Clinical Psychology, 57, 42-58. 
Messerchmidt, J. W., (2018) Hegemonic masculinity : formulation, reformulation, and amplification, Lanham : Rowman \& Littlefield.

Moret, C., Isaac, M., Briley, M., (2009) 'Problems associated with long-term treatment with selective serotonin reuptake inhibitors', Journal of Psychopharmacology, 23(8), 967974.

Mullen, C., Doherty, M., Coates, R., and Tilley, M., (2014) 'Women's experiences of coping with the side-effects of antidepressant medication', Psychology \& Health, 29, pp. 1388-1406.

O’Brien, R., Hunt, K., and Hart, G., (2005) "It's caveman stuff, but that is to a certain extent how guys still operate': Men's accounts of masculinity and help seeking', Social Science \& Medicine, 61, pp. 503-516.

Read, J., Cartwright, C., and Gibson, K., (2014) 'Adverse emotional and interpersonal effects reported by 1829 New Zealanders while taking antidepressants', Psychiatry Research, 216, pp. 67-73.

Ridge, D. and Ziebland, S., (2006) "The old me could never have done that': how people give meaning to recovery following depression', Qualitative health research, 16(8), pp. 1038. 
Robertson, S., Bagnall, A., Walker, M., (2015) 'Evidence for a gender-based approach to mental health: identifying the key considerations associated with "being male"', an Evidence Check rapid review by the Sax Institute for the Movember Foundation Ryan, G. W., and Bernard, H. R., (2003) 'Techniques to Identify Themes', Field Methods, 15(1), pp. 85-109.

Sawada, N., Uchida, H., Suzuki, T., Watanabe, K., Kikuchi, T., Handa, T., Kashima, H., (2009) 'persistence and compliance to antidepressant treatment in patients with depression: a chart review', BMC Psychiatry, 9, 38

Schreiber, R., (1996) '(Re)Defining My Self: Women's Process of Recovery from Depression', Qualitative Health Research, 6(4), pp. 469-491.

Schreiber, R., and Hartrick, G., (2002) 'Keeping it together: how women use the biomedical explanatory model to manage the stigma of depression', Issues in Mental Health Nursing, 23(2), 91-105

Seidler, Z. E., Rice, S. M., River, J., Oliffe, J. L., and Dhillon, H. M., (2018) 'Men's Mental Health Services: The Case for a Masculinities Model', Journal of Men's Studies, Vol. 26(1), $92-104$ 
van Servellen, G., Heise, B. A., and Ellis, R., (2011) 'Factors associated with antidepressant medication adherence and adherence-enhancement programmes: a systematic literature review', Mental Health in Family Medicine, 8(4), 255-271

Sirey, J. A., Bruce, M. L., Alexopoulos, G. S., Perlick, D. A., Friedman, S. J., Meyers, B. S. (2001) 'Stigma as a barrier to recovery: perceived stigma and patient-rated severity of illness as predictors of antidepressant drug adherence', Psychiatric Services, 52(12), $1615-20$

Smith, D., T., Mouzon, D., M., and Elliott, M., (2018) 'Reviewing the Assumptions About Men's Mental Health: An Exploration of the Gender Binary', American Journal of Men's Health, 12(1), pp. 78-89.

Stevenson, F., and Knudsen, P., (2008) 'Discourses of agency and the search for the authentic self: The case of mood-modifying medicines', Social Science \& Medicine, 66(1), pp. $170-181$.

Stewart, D. and Harmon, K., (2004) 'Mental health services responding to men and their anger', International Journal of Mental Health Nursing, 13, 249-254

Ussher, J., (2010) 'Are we medicalizing women's misery? A critical review of women's higher rates of reported depression', Feminism \& Psychology, 20, pp. 9-35. 
Vogel, D. L., Heimerdinger-Edwards, S. R., Hammer, J. H., and Hubbard, A., (2011) 'Boys don't cry: Examination of the links between endorsement of masculine norms, selfstigma, and help-seeking attitudes for men from diverse backgrounds', Journal of Counseling Psychology, 58, pp. 368-382.

Voils, C., Steffens, D., Flint, E., and Bosworth, H., (2005) 'Social support and locus of control as predictors of adherence to antidepressant medication in an elderly populations', American Journal of Geriatric Psychiatry, 13(2), 157-65.

Williams, G., (1984) 'The genesis of chronic illness: narrative re-construction', Sociology of health \& illness, 6(2), pp. 175-200 